\title{
The allelochemical tannic acid affects the locomotion and feeding behaviour of the pond snail, Lymnaea stagnalis, by inhibiting peripheral pathways
}

\author{
Ágnes Vehovszky ${ }^{1}\left[\right.$ [ $\cdot$ Réka Horváth $^{1} \cdot$ Anna Farkas $^{1} \cdot$ János Győri $^{1} \cdot$ Károly Elekes $^{1}$
}

Received: 10 April 2019 / Accepted: 22 July 2019 / Published online: 22 August 2019

(c) The Author(s) 2019

\begin{abstract}
(1) The effect of tannic acid (TA), a dominant component of plant allelochemicals, was investigated on the locomotion and feeding of the pond snail, Lymnaea stagnalis. The effect of TA on the neuronal background underlying feeding activity was also analysed. (2) TA affected the spontaneous locomotion and of juvenile snails in a concentration-dependent way. Low $(10 \mu \mathrm{M})$ TA concentration resulted in an increased (sliding or swimming) activity compared to the control; meanwhile, high $(100 \mu \mathrm{M}) \mathrm{TA}$ concentration inhibited the locomotion of the animals. (3) Low $(10 \mu \mathrm{M})$ TA concentration increased the frequency of sucrose-evoked feeding of intact animals, whereas high $(100 \mu \mathrm{M})$ TA concentration resulted in significantly longer feeding latency and decreased feeding rate. The feeding changes proved to be partially irreversible, since after $48 \mathrm{~h}$ maintained in clear water, the animals tested in $100 \mu \mathrm{M}$ TA previously still showed lower feeding rate in sucrose. (4) Electrophysiological experiments on semi-intact preparations showed that application of $100 \mu \mathrm{M}$ TA to the lip area inhibited the fictive feeding pattern of central neurons, the cellular response to sucrose. (5) On isolated CNS preparation, $100 \mu \mathrm{M} \mathrm{TA}$ applied in the bathing solution, however, failed to inhibit the activation of the central feeding (CPG) interneurons following application of extracellular dopamine. Our results suggest that TA affects both afferent and efferent peripheral functions in Lymnaea. TA reduces feeding activity by primarily blocking feeding sensory pathways, and its negative effect on locomotion may imply sensory pathways and/or ciliary activity.
\end{abstract}

Keywords Allelochemicals $\cdot$ Tannic acid $\cdot$ Lymnaea $\cdot$ Feeding $\cdot$ Locomotion $\cdot$ Peripheral pathways

\section{Introduction}

\section{Tannins}

Tannins, a heterogenous group of high molecular weight (500-3000 Da) water-soluble compounds, members of the even more complex family of polyphenolics, are among the most studied plant secondary metabolites from a chemical-ecological aspect (Salminen and Karonen 2011). The synthesis of these phenolic compounds is not restricted to plant species found in particular habitats, as it is also

Ágnes Vehovszky and Réka Horváth have contributed equally to this work.

Ágnes Vehovszky

vehovszky.agnes@okologia.mta.hu

1 MTA Centre for Ecological Research, Balaton Limnological Institute, Tihany 8237, Hungary present in cereals, legumes, nuts, fruits, vegetables, beverages and red wines (Scalbert and Williamson 2000; Serrano et al. 2009), confirming their abundance in our diet (approx. $0.1-1 \mathrm{~g} /$ day). Tannins play an essential role in the survival of plants because of their protective capacity against various biotic and abiotic stressors (Haukioja 2005; Smeriglio et al. 2017). Their biological activity is based on their capability of precipitating macromolecules (particularly proteins) and metals, and to cause oxidative stress by auto-oxidation or enzymatic processes (Salminen and Karonen 2011). Polyphenolic compounds including tannins have numerous different effects depending on both their chemical structure and environment. For example, they may evoke contradictory effects in the mostly alkalic gut of insects and the acidic alimentary tract of mammals (Salminen and Karonen 2011). This may partially explain why tannins have anti-nutritive effects on numerous herbivorous insects and antimicrobial activities on bacteria (Appel and Schultz 1994; Graca and Barlocher 1999; Marin et al. 2015), but exert positive dietary 
effect in mammals, including human (Scalbert and Williamson 2000; Harbertson et al. 2008; Serrano et al. 2009; Sieniawska 2015). Intracellularly, tannins are also characterized by a high diversity of negative effects (Anku et al. 2017), as well as positive pharmacological and biochemical actions, including antioxidant and radical scavenging and anti-cancerous effects (Gollucke et al. 2013; Sieniawska 2015; Skrovankova et al. 2015; Smeriglio et al. 2017).

In natural waters, the presence of tannins together with an even more complex group of humic substances is resulted by vegetative degradation (decomposition of leaves, roots, etc.). Their concentrations vary in different aquatic environments with the highest level detected in the coloured water of bogs, while in some Canadian rivers and lakes tannin concentration was measured between 0.5 and $4 \mathrm{mg} / \mathrm{l}$ (Afghan and Chau 2017). We should also note that at present no generally established analytical methods are available to detect tannins alone (Salminen and Karonen 2011). The living tissues of several aquatic plants (incl. Myriophyllum) were shown to contain high amount of polyphenolics (3-150 mg/g dry weight), and also release them in the environment $(2-4 \mathrm{mg} / \mathrm{g}$ dry wt of tannic acid equivalent) in a 10-day period (Gross et al. 1996; Choi et al. 2002; Li et al. 2004).

In addition to their deterrent functions (Coley et al. 1985), hydrolysable and condensed tannins can perturb the development and growth of numerous aquatic herbivorous insects (Feeny 1976; Choi et al. 2002). Tannins can reduce the size of the female pupae of the autumnal moth, Epirrita autumnata, resulting in a decreased number of laid eggs and deterioration of the physical state of the adult insect (Haukioja and Neuvonen 1985; Tikkanen et al. 2000), and also causing a higher risk of predation mortality (Feeny 1976).

Both terrestrial and aquatic molluscs provide good models to indicate toxicity and for the analysis of toxic effects on their nervous systems (Salánki et al. 2003; Rittschof and McClellan-Green 2005; Das and Khangarot 2011). Although different allelochemicals, among them tannins, are suggested to be a molluscicide effect in case of snails (Singh et al. 1996; Rawani et al. 2014), our knowledge is limited regarding the possible mode of action of their harmful/sublethal effects on behaviour and neuronal mechanisms.

In our present study, two forms of behaviour (locomotion and feeding) were monitored in the presence of the commercially available tannic acid (TA). Both locomotion and feeding, as well as the neuronal basis of their regulation, have widely been studied in gastropods, including our model animals, Lymnaea stagnalis (for review see Chase 2002; Benjamin 2012).

\section{Locomotion}

In gastropods two major forms of locomotion, crawling and swimming, have been distinguished (for review see Chase
2002). Crawling, mentioned also sometimes as sliding, is typical for both terrestrial and aquatic gastropod species, although the cellular execution of the movement is different; in case of terrestrial species it is based on the rhythmic contraction of the foot musculature (Helix, Limax), whereas in the case of aquatic animals the forward movement is performed by the beating of cilia covering the sole of the foot (Lymnaea, Planorbis). Swimming is mainly confined to Opistobranchiata, performing the movement either by paddles or wings (Clione), whereas some benthic species have a sliding movement, moving by a typical undulation of the whole body resembling crawling during escape (Tritonia). In the case of Aplysia species, some like A. californica perform crawling by using their foot, whereas others like $A$. fasciata use a pair of parapodia originating from the foot for swimming.

The target of our present study, the pond snail, Lymnaea stagnalis, as an aquatic species displays mainly ciliary-based crawling (sliding) (Chase 2002). In addition, we could distinguish three further forms of locomotion during our present research: swimming, floating and sticking. These forms of locomotion and their regulatory mechanisms have not yet been studied in Lymnaea.

The neuronal regulation of locomotion is based on motoneurons located in the pedal ganglia controlled by a central pattern generator (CPG) network in the CNS. Regarding the transmitters involved, two neuronal mechanisms have been identified. The ciliary movements are modulated by serotonergic mechanisms originating from the central (pedal) neurons (Sidorov and Kazakevich 2001; Pavlova 2010), while the foot muscle contractions are under dopaminergic regulation (Pavlova 2013, 2019). The spontaneous locomotion of Lymnaea can easily be monitored and quantified (Pyatt et al. 2002; Dhara et al. 2017; Ford et al. 2018).

\section{Feeding}

The feeding behaviour of Lymnaea is a good indicator when detecting neuronal changes behind neurotoxic effects (Kemenes et al. 1990; Vehovszky et al. 2007), ageing (Arundell et al. 2006) or learning processes (Staras et al. 1998).

Consummatory feeding of Lymnaea is a result of the highly coordinated contractions of the buccal musculature, executed in a sequence starting by radula protraction, followed by radula retraction and then swallowing. This rhythmic activity of feeding is regulated by a central pattern generator (CPG) network of interneurons located in the CNS (Benjamin 1983; Benjamin and Elliott 1989). The neurons of the CPG activate each other as well as other members (both interneurons and motoneurons) of the feeding system by a cyclic pattern of synaptic inputs. While recording intracellularly, a rhythmic activity pattern called fictive feeding allows to easily identify the central feeding neurons and 
analyse their possible modulation in both semi-intact and isolated CNS preparations. Activating the feeding rhythm of the central network, moreover, does not necessarily requires peripheral inputs, as fictive feeding can also be triggered in the isolated CNS preparation either by intracellular stimulation of higher-order feeding interneurons (Elliott and Benjamin 1985; McCrohan and Kyriakides 1989; Vehovszky and Elliott 2001) or by extracellularly applied monoamines (dopamine [DA], octopamine, Kyriakides and McCrohan 1989; Vehovszky et al. 1998).

\section{Aims}

Based on the above, tannic acid (TA), a specific plant polyphenol (belonging to the galloylglucose family), was selected for our present study to clarify its potential effect on different behaviours (locomotion and feeding) of a model invertebrate, the pond snail, Lymnaea stagnalis L. Applying electrophysiological methods, we also analysed the TAevoked changes in the neuronal network responsible for the regulation of feeding activity.

\section{Materials and methods}

\section{Animals}

Adult snails were collected locally in the Lake Balaton region (Hungary) between May and September 2018, maintained in 120-L glass aquaria filled with aerated filtered Balaton water and fed on lettuce ad libitum. The Balaton water taken from the open water area (about $100 \mathrm{~m}$ from the shore, depth 3-3.5 m) was free from macrophytes, the natural sources of polyphenols in freshwater. Juvenile specimens of Lymnaea stagnalis originated from our laboratorybred populations. All the experimental animals were isolated 2-4 days before testing and placed in 15-L containers filled also with aerated filtered Balaton water, in the absence of food.

\section{Chemicals}

All chemicals used for the preparation of the Lymnaea physiological saline (Magoski et al. 1995), as well as tannic acid (TA), dopamine hydrochloride (DA) and sucrose were purchased from SIGMA (Budapest, Hungary). The testing solutions containing 10 or $100 \mu \mathrm{M}$ TA were freshly prepared in Balaton water immediately before the locomotion and feeding assays. Sucrose solution $(100 \mathrm{mM})$ was prepared in Balaton water and used during the feeding tests, and for experiments on semi-intact preparations it was applied on the lip area. For the electrophysiological test on isolated CNS preparations, DA was applied from a pipette directly into the experimental chamber, while TA prepared in Lymnaea physiological saline was applied in the bath by perfusion.

\section{Behavioural tests}

\section{Locomotion}

In the locomotion study, P2 juvenile snails (Lymnaea stagnalis) were used (for staging see Croll and Chiasson 1989). The reason for using juveniles and not adults was that observing and tracing the different (active and passive) forms of locomotion, which are already both identical with those of the adults at this time of development, were easier compared to observing the larger size adult animals. As already mentioned above (see Introduction), the following locomotory forms could be distinguished: sliding (crawling), swimming, sticking and floating. Sliding meant moving on the glass surface of the container, swimming was defined as moving in the water by slow undulations towards a given direction, whereas floating was determined as a non-moving, immobile state of the animals in the water and sticking was the state of an animal attached motionless for longer time (several minutes) to a surface such as glass wall, stone or a leaf. The first two behaviours were considered as measures of activity, whereas the last two those as passivity.

The specimens of the two experimental groups $(n=10$ in each) were placed into small $(2.5 \mathrm{ml})$ glass containers containing $10 \mu \mathrm{M}$ or $100 \mu \mathrm{M}$ TA diluted in filtered Balaton water. A third group $(n=10)$ served as control and was maintained only in filtered Balaton water. All the animals were exposed to TA and observed individually in every case. An experimental trial lasted for $60 \mathrm{~min}$. Altogether 10 trials were performed at both TA concentrations within a period of a week. Following each 60-min trial, the duration of both the active and passive periods was summarized and their percentage rates were calculated and then averaged.

\section{Feeding}

To characterize the feeding behaviour of the animals, we applied the already established feeding assay performed on intact Lymnaea stagnalis specimens when sucrose solution provided the stimulus evoking consummatory feeding (Kemenes et al. 1986). This behaviour was quantified by its latency (the time duration between the application of feeding stimulus and start of feeding) and the feeding rate (the frequency of the mouth opening/closing cycles). The animals were individually placed into a Petri dish filled with $100 \mathrm{mM}$ sucrose solution dissolved in Balaton water (control) or in a solution containing $10 \mu \mathrm{M}$ or $100 \mu \mathrm{M}$ TA in Balaton water (treated animals). When the animals started feeding within 2 min (they responded to sucrose) the feeding latency (in 
seconds) and feeding frequency (bites/min) were measured. After the feeding assay finished the group of animals (the individual groups separately) were put back in the 15-L container filled with Balaton water until the next day's testing.

\section{Electrophysiological experiments on semi-intact preparations}

We also used a simplified, but functional feeding model, a semi-intact preparation consisting of the CNS attached with peripheral nerves to the sensory areas (mouth, lip) of the head region of the animal, meanwhile simultaneously recording the intracellular activity of the buccal feeding neurons (Benjamin and Elliott 1989; Staras et al. 1999a, b). The preparation and recording techniques have been described previously in more detail (Kemenes et al. 1997; Vehovszky et al. 2004). The individual neurons were identified visually by their size, location and intracellular firing pattern after microelectrode penetration (Vehovszky and Elliott 2001). As the feeding stimulus, $100 \mathrm{mM}$ sucrose was dissolved in filtered Balaton water and applied to the lips from a pipette, followed by the application of 10 or $100 \mu \mathrm{M} \mathrm{TA}$, while the CNS compartment was perfused continuously with normal Lymnaea saline (Magoski et al. 1995). Before and after the applications, the lips were washed with filtered Balaton water.

\section{Electrophysiological experiments on isolated CNS preparations}

For testing the direct cellular effects of TA on feeding neurons, we also recorded their intracellular activity in isolated CNS preparations. The intracellular recording was performed by using filamented (5-8 $\mathrm{M} \Omega$ resistance) borosilicate glass microelectrodes filled with a mixture of $4 \mathrm{M}$ potassium acetate and $0.4 \mathrm{M}$ potassium chloride. The intracellular signals were recorded by an Axoclamp 2B amplifier, sampled and stored at $1-2 \mathrm{kHz}$ using a National Instruments (NI 6035E) AD converter and a DasyLab 5.6 software.

\section{Data processing, statistics}

To analyse the locomotor activity, the duration spent in active (sliding and swimming) and passive (floating and sticking) periods was measured, then the two (active and passive) categories were summarized separately, and their percentage rate was calculated after each 60 -min trial. Thereafter, the results were averaged in (case of) the three experimental groups. Data are presented as mean \pm SD.

The frequencies of fictive feeding $(\mathrm{F})$ were calculated by the time intervals in seconds $(\mathrm{T})$ between the rhythmic synaptic inputs recorded from buccal feeding motoneurons (for example N2 inputs on B4 or B8 neurons) as $F=(1 / \mathrm{T}) * 60$; (cycles/min).

Data are presented as mean \pm SD. Statistical tests were performed using Student's $t$ test for significance level.

\section{Results}

\section{Effect of TA on locomotion}

In the control group, initially sliding prevailed as spontaneous locomotor activity, presumably as a result of the animals monitoring their new environment, but later the number and duration of sticking phases were constantly increasing, reaching nearly the fifty per cent ratio of the whole period recorded (Fig. 1). A relative consistency was observed regarding swimming, in the course of which the snails spent $5-7 \%$ of their entire active state in this form of behaviour, independently of the TA concentration applied. The ratio between the time spent in active or passive states was approx. 1:1 (51 vs. 49\%) during a 60-min trial (Fig. 2). The animals spent $44 \%$ of the trial with sliding and a further $7 \%$ with swimming, while they were stuck for $41 \%$ and floated $8 \%$ of the total time.

Following the application of $10 \mu \mathrm{M} \mathrm{TA}$, the animals could be separated in two subgroups, according to their displayed activity. The behaviour of the first subgroup $(n=5)$ did not show notable alteration compared to the control, while in the second subgroup $(n=5)$ the snails displayed an elevated level of locomotor activity (hyperactivity), manifested in a more than $40 \%$ increase of active periods, compared to the control. The snails spent $92.5 \%$ of the time in active phases, within which the sliding activity was $85.5 \%$ and the swimming activity made up about $7 \%$. Additionally, the snails remained stuck during $5.5 \%$ of the total trial time $(60 \mathrm{~min})$, whereas in the rest (2\%) they floated. Summarizing the data of the two subgroups $(n=10)$ exposed to $10 \mu \mathrm{M}$ TA, the active-passive ratio was about 2:1 (68 vs. 32\%). The snails spent $63 \%$ of the time with sliding, 5\% with swimming, $22 \%$ with sticking and $10 \%$ with floating (Fig. 2).

At high concentration $(100 \mu \mathrm{M}) \mathrm{TA}$ treatment, an elevated locomotion dominated the first $15 \mathrm{~min}$ of the 60 -min observation/exposition period, presumably referring to the escape of the snails from the unpleasant environment. This phenomenon faded away quickly and followed gradually by a general passivity, changing the active/passive ratio strongly for inactivity (Figs. 1, 2). Compared to the $10 \mu \mathrm{M}$ TA-treated group, a 1:3 (23\% vs. $77 \%$ ) active-passive ratio could be observed. Furthermore, significant changes were also found both in the duration of active and passive states in comparison with the control group (1:3 vs 1:1). The animals were in sliding state for $16 \%$ of the total time and spent $7 \%$ of the experimental period $(60 \mathrm{~min})$ with swimming. The sticking 
Fig. 1 Time and dose-dependent effect of TA on the locomotion of juvenile snails (Lymnaea stagnalis). $X$ axis shows the different forms of locomotion (Sl sliding, $S w$ swimming, $F l$ floating, St sticking) in Balaton water (control) and in 10, $100 \mu \mathrm{M}$ TA. $Y$ axis: time spent in a particular form of behaviour during the $900 \mathrm{~s}$ (15 min) observation period

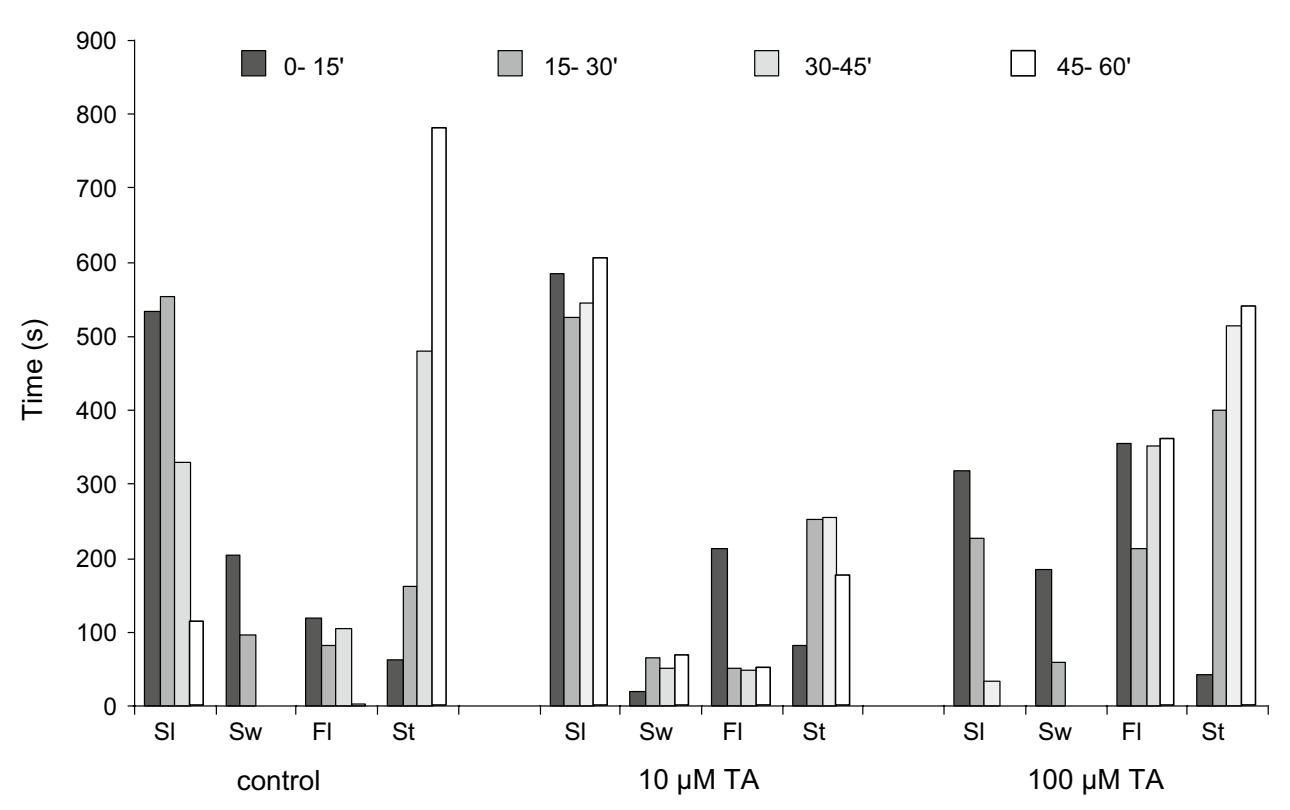

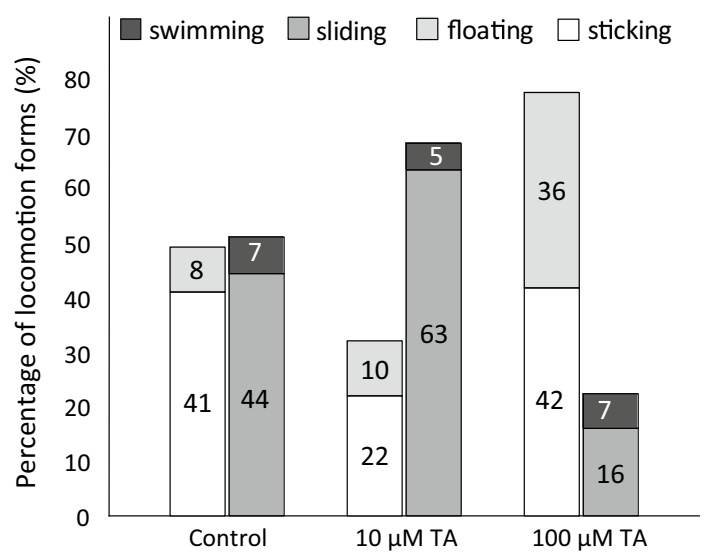

Fig. 2 Concentration-dependent effect of TA on the locomotion of juvenile snails (Lymnaea stagnalis). In lower concentration $(10 \mu \mathrm{M})$ TA increased the ratio of active (swimming and sliding) versus passive (floating and sticking) periods of locomotion, seen as higher level of sliding activity and with less sticking periods. Higher, $100 \mu \mathrm{M}$ TA concentration resulted in the predominance of passive forms with almost equal contribution of sticking and floating. Mean \pm SD; $n=10$ in each group. Total time of a trial was $60 \mathrm{~min}$ $(100 \%)$. Numbers indicate the percentage values of each form of locomotion

period worked out $42 \%$, whereas this value was $36 \%$ concerning floating (Fig. 2).

\section{Effect of TA on feeding}

In preliminary experiments (before testing), three groups of animals (12 specimens in each) were separated and the same groups were tested each consecutive day in sucrose-containing solution, in order to allow them to be accommodated to the experimental conditions. As a result, all the animals responded to sucrose and displayed shorter duration of feeding latency, while the feeding frequencies seemed less scattered (giving smaller error values) during the testing period (Fig. 3a-d).

On the experimental day, the snails were placed in Petri dishes containing either $100 \mathrm{mM}$ sucrose (control, group 1) or mixture of sucrose and freshly dissolved TA (group 2: $10 \mu \mathrm{M}$ TA, group 3: $100 \mu \mathrm{M} \mathrm{TA}$, respectively). Although the values of feeding latency were not significantly different in any $(1,2,3)$ group (Fig. 3b), members of the $10 \mu \mathrm{M}$ TA exposed group showed a slightly increased feeding rate $(18.13 \pm 4.1 \mathrm{bites} / \mathrm{min})$, and the animals tested in $100 \mu \mathrm{M}$ TA showed a significantly lower feeding frequency ( $7.5 \pm 3.2 \mathrm{bites} / \mathrm{min})$, as compared with the control animals tested on the same day in sucrose $(15.1 \pm 1.8 \mathrm{bites} / \mathrm{min}$, Fig. 3b, group 1). After the feeding tests, all the animals were placed again in their home tanks filled with Balaton water, and next day the same groups were re-assayed by the same protocol (group 1 in sucrose only, group 2 sucrose in $10 \mu \mathrm{M} \mathrm{TA}$, and group 3 sucrose in $100 \mu \mathrm{M} \mathrm{TA}$ ). All the animals tested in TA showed significantly different feeding parameters from the control group (Fig. 3c). The feeding latency became longer both in $10 \mu \mathrm{M}$ and $100 \mu \mathrm{M}$ TA-tested animals (groups 2, 3, 8.9 \pm 2.84 and $17.5 \pm 6.3$, respectively), compared to the members of the control (group 1, $6.9 \pm 1.3 \mathrm{~s}$ ), and the feeding frequency showed lower values in the TA-treated groups 2 and $3(14.8 \pm 1.67 \mathrm{bites} / \mathrm{min}$ and $8.0 \pm 6.3 \mathrm{bites} / \mathrm{min}$, respectively), compared to the control group 1 (16.2 \pm 1.4 bites $/ \mathrm{min})$. All the TA-treated animals were re-assayed again 2 days later in Balaton water containing only sucrose (Fig. 3d). The snails tested in $100 \mu \mathrm{M}$ TA previously (group 3) still showed significantly lower 
a

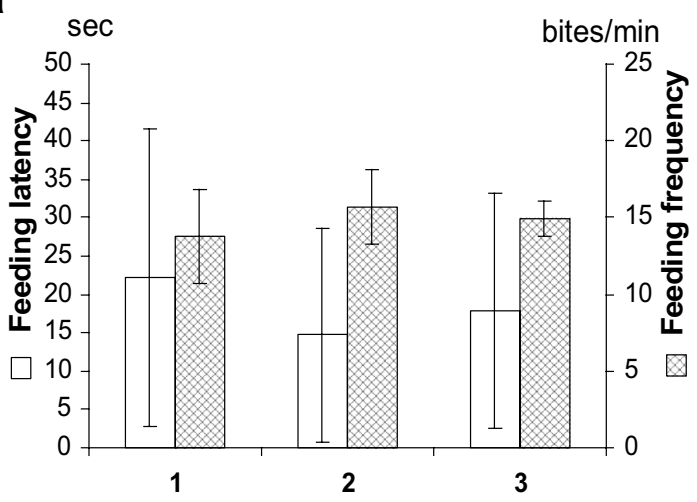

C



Fig. 3 Feeding tests performed on snails following the application of $100 \mathrm{mM}$ sucrose show altered feeding parameters in the presence of TA. a All three groups $(1,2,3)$ tested in Balaton water show similar, not significantly different feeding latency and feeding rate. b An increased feeding rate of group $2(10 \mu \mathrm{M}$ TA $)$ and a significantly decreased feeding frequency in group $3(100 \mu \mathrm{M}$ TA) are seen compared to the feeding response of control animals tested in water (group 1). c Repeated tests next day (1: sucrose; 2: sucrose $+10 \mu \mathrm{M}$

feeding rate compared to the controls $(8.58 \pm 2.2 \mathrm{bites} / \mathrm{min}$ and $17.0 \pm 1.47 \mathrm{bites} / \mathrm{min}$, respectively).

\section{Effect of TA on semi-intact preparations}

On semi-intact (head-CNS) preparations, first we tested the peripheral sensory-central pathways by applying $100 \mathrm{mM}$ sucrose to the chemosensory head areas (lip, mouth). A positive intracellular feeding response was considered when the identified feeding neurons displayed the rhythmic pattern of fictive feeding (sequence of synaptic inputs or firing activity) immediately after sucrose application as seen in Fig. 4, which represent an example of the 6 experiments out of 8 preparations, when sucrose response was evoked successfully and repeatedly.

Without peripheral stimulation, the buccal feeding neurons were characterized by a rather irregular activity pattern, and water applied to the lip (representing a tactile stimulus) b
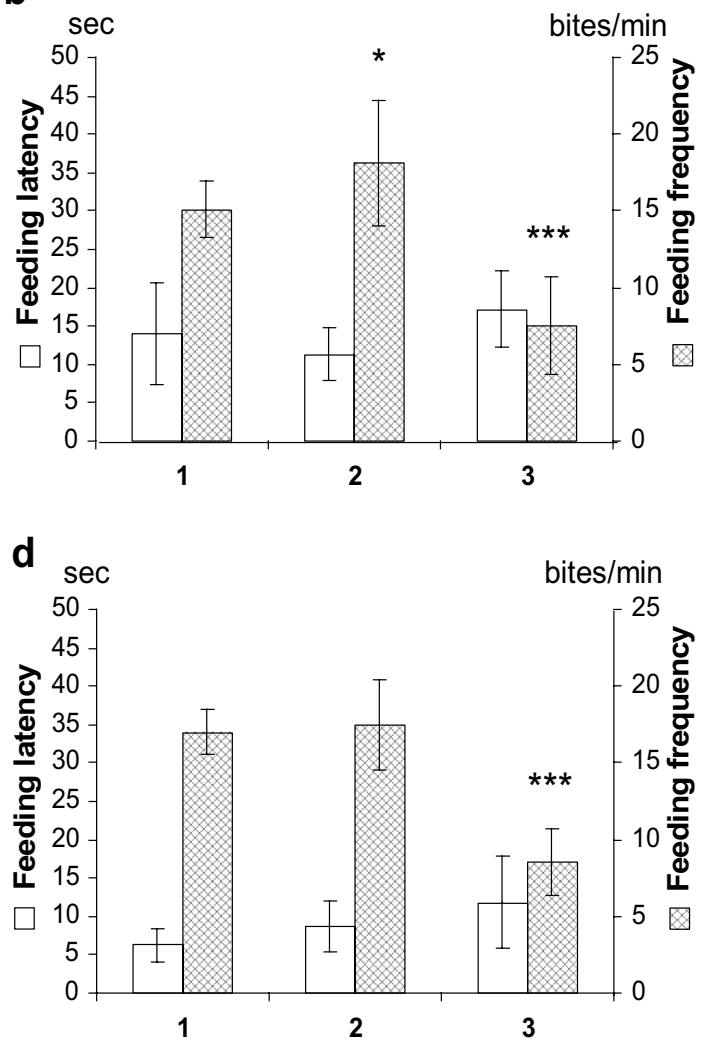

TA; 3: sucrose $+100 \mu \mathrm{M}$ TA) show significantly longer latency and lower feeding rate in both treated groups $(2,3)$. d After $48 \mathrm{~h}$ all the groups $(1,2,3)$ were tested in sucrose only, and group 3 still displayed decreased feeding rate. Left axis shows latency in seconds, and the right axis shows the feeding frequencies expressed as bite/ min (mean $\pm \mathrm{SD} ; \mathrm{n}=12$ in each group). ${ }^{*} p<0.05 ; * * p<0.01$; $* * * p<0.001$

did not alter their intracellular activity (Fig. 4a1, c1). After application of $100 \mathrm{mM}$ sucrose solution onto the lip area, the same neurons displayed a synchronous, rhythmic activity formed by a series of (excitatory and inhibitory) synaptic inputs, indicating activation of the CPG feeding network (Fig. 4a1). For example regular inhibitory (N1, N2 phase) inputs were recorded from the B8 motoneuron, simultaneously with the strong (N1 phase) excitatory inputs (depolarization and bursting) on the B1 motoneurons (Fig. 4a2).

Applying $100 \mu \mathrm{M}$ TA onto the lip-mouth area did not alter the spontaneous intracellular pattern of feeding neurons, but prevented the intracellular feeding response of the neurons after sucrose application (Fig. 4b1, 2). As a result, the activity pattern of individual feeding neurons did not display inputs of fictive feeding, indicating that sucrose failed to trigger the neuronal network of the feeding CPG system (Fig. 4b2). The feeding response of the central neurons only partially recovered after the lip-mouth area was washed by 
a1



N1 N2 N3

a2

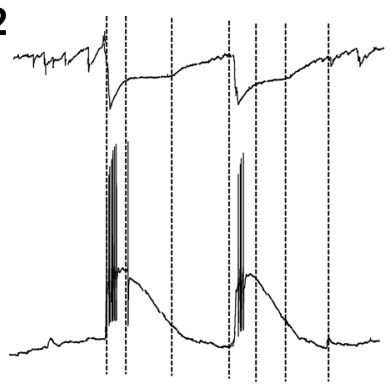

b2
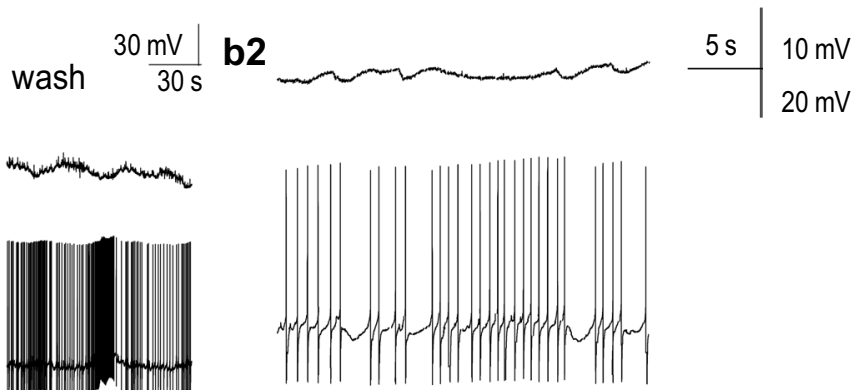

c2

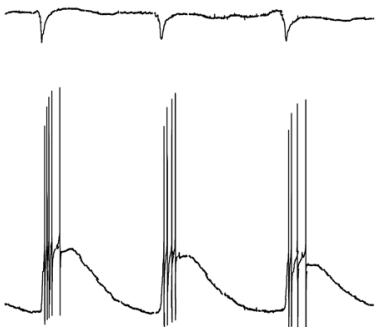

Fig. 4 Preliminary application of TA prevents sucrose response. A Simultaneous recording from two buccal motoneurons (B8, B1) during Balaton water application (W), followed by $100 \mathrm{mM}$ sucrose (Suc) applied to the lip area (a1). Sucrose-evoked rhythmic activity is seen as series of inhibitory inputs on B8 neuron and depolarization with action potentials on $\mathrm{B} 1$ neuron, respectively. N1, N2, N3 indicate the phases of fictive feeding (a2). B Application of $100 \mu \mathrm{M}$

Balaton water for $20 \mathrm{~min}$ before the application of sucrose was repeated again (Fig. 4c1, 2).

\section{Effect of TA on isolated CNS preparation}

Although both the feeding tests carried out on intact animals, and the electrophysiological results obtained from semi-intact preparations suggest modulation of the sensory pathways by TA, it could not be excluded that TA also directly targets the interneurons of the central feeding CGP network, resulting in their decreased ability to evoke feeding pattern.

To activate the central feeding (CPG) network in the isolated CNS preparation, we performed a drop application of $100 \mu \mathrm{l}$ of $1 \mathrm{mM}$ DA directly in the experimental chamber during continuous perfusion with normal saline
TA did not change the spontaneous activity, and sucrose dissolved in TA solution (Suc +TA) fails to evoke the feeding rhythm (b1), as rhythmic synaptic inputs are not visible in B8 or B1 neurons (b2). C After 20-min washing, the lip with water the sucrose-evoked intracellular response recovered (c1) and the cyclic synaptic inputs re-appear in the intracellular activities of feeding neurons. (c2). Representative example of the experiments carried out on 6 independent preparations

(Fig. 5, a representative example of independent experiments on 6 preparations). This kind of application enabled a phasic concentration change of DA and washing out of the transmitter effect in 4-5 min. Activation of the CPG network by DA application was well detected by the altered activity of feeding motoneurons as rhythmic pattern of synaptic inputs and bursts of action potentials appeared (Fig. 5a1). This dopamine-evoked rhythmic activity, for example a series of $\mathrm{N} 2$ phase synaptic inputs on B4 motoneuron (Fig. 5a2), formed a similar pattern as we recorded in semi-intact preparations when sucrose was applied to the lip area (Fig. 4a2). TA $(100 \mu \mathrm{M})$ applied in the perfusion chamber did not change the spontaneous activity or the DA evoked cellular responses of the feeding neurons. The frequency values of the spontaneous activity did not show significant differences in normal 


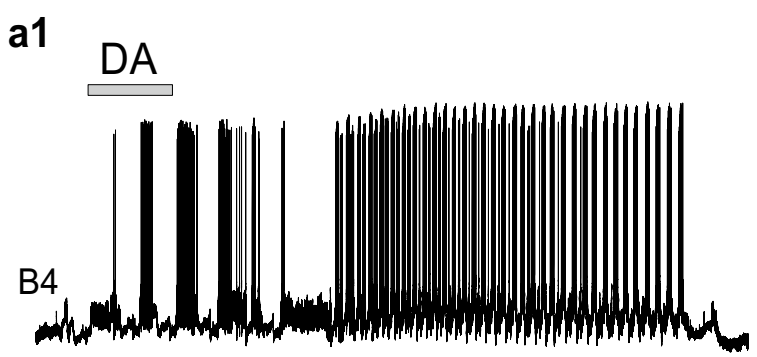

b1

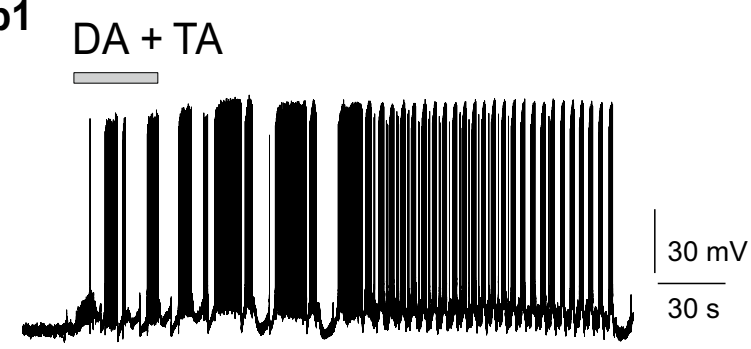

a2
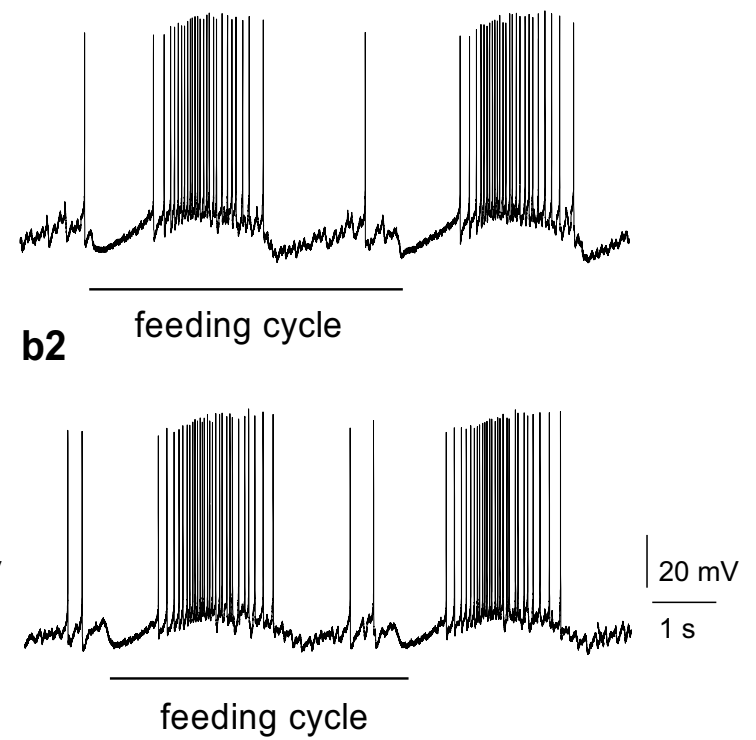

the intervals between the $\mathrm{N} 2$ phase synaptic inputs on B4 motoneuron (a2) does not show significant changes after DA application (b2). Representative example of independent experiments carried out on 6 preparations



b



Fig. 6 a In isolated central nervous system TA did not alter the frequencies of DA evoked fictive feeding. a Prior to DA application (control) the spontaneous rhythm of intracellular activity (with frequencies around 5 cycles/min) is switched to a threefold frequency

saline, in $100 \mu \mathrm{M}$ TA or after washing out with saline again $(4.0 \pm 1.0,5.0 \pm 0.7$ and $4.1 \pm 0.9$ cycles $/ \mathrm{min}$, respectively). Neither was the dopamine-evoked fictive feeding modulated by the presence of TA in the perfusion chamber, as the frequency of feeding rhythm (measured by the length of the feeding cycles) did not change either (Fig. 5b1, b2). increase after applying $100 \mu 11 \mathrm{mM} \mathrm{DA}$ in the perfusion chamber (dotted line). b Diagrams showing no significant differences in frequencies in normal saline (NS), in the presence of $100 \mu \mathrm{M}$ TA, or after washing with saline again (Wash)

While comparing the top frequencies of DA-evoked fictive feeding, no significant differences were seen in normal saline (control), in the presence of $100 \mu \mathrm{M}$ TA or after washing out $(15.0 \pm 1.29 ; 15.48 \pm 1.18$; and $16.7 \pm 2.1$ cycles/min, respectively (Fig. $6 a, b)$. 


\section{Discussion}

\section{Behavioural alterations evoked by TA on snails}

Our experimental results revealed dose-dependent (both stimulatory and inhibitory) effects of TA on the behaviour (locomotion and feeding) of the pond snail, Lymnaea stagnalis, following the application of this allelochemical. The lower $(10 \mu \mathrm{M})$ concentration of TA applied probably is about the individual (stimulus-) threshold concentration, as half of the animals did not show differences in their locomotory activity compared with the control group, while in the other group of the animals the spontaneous locomotion was slightly stimulated. Additionally, the frequency of the sucrose-evoked feeding response (feeding rate) was also significantly increased in $10 \mu \mathrm{M} \mathrm{TA}$. A weakly facilitated locomotory activity of snails was also observed initially, when high $(100 \mu \mathrm{M})$ concentration of TA was applied, particularly during the first 15-min period of exposure, but later TA inhibited the locomotion. Higher concentration $(100 \mu \mathrm{M}) \mathrm{TA}$ also reduced the feeding, resulting in longer feeding latency and lower biting frequency values of intact animals. Consequently, high concentration $(100 \mu \mathrm{M})$ of TA acted as an inhibitor of both locomotion and feeding, resulting in a long-lasting non-moving, passive state of the exposed animals, and this concentration of TA also decreased feeding activity of the intact animals.

The neuromodulator role of monoamines has well been established in the regulation of snail locomotion (see Pavlova 2019). Sliding (crawling), which is characteristic for Lymnaea, is based on the activity of the ciliated epithelial cells of the sole, and ciliary movement is modulated by serotonergic mechanisms originating from the central (pedal) neurons (Sidorov and Kazakevich 2001; Pavlova 2010). The facilitatory role of serotonin has also been demonstrated during the late period of Lymnaea embryogenesis (Filla et al. 2009).

It is assumed that TA acts directly on the ciliary activity either by directly influencing the 5-HT receptors or hitting the serotonergic regulatory pathway(s) through an afferentefferent system, including receptor cells located on the surface of the foot and the central (pedal) serotonergic efferent elements. The slow forwarding swimming movement of the juvenile snails, observed in our present study, may also be influenced by TA directly on the foot musculature. In Lymnaea contractions of the foot musculature are primarily controlled by dopaminergic elements of the nervous system (Pavlova 2013, 2019), and the involvement of acetylcholine (ACh) in the snail muscular activity was also suggested, particularly, in terrestrial snails (Walker and Holden-Dye 1991; Panchin et al. 1995; Krajcs et al. 2014). Most recently TA was shown to inhibit acetylcholinesterase (AChE) enzyme activity in vitro (Kim et al. 2018); therefore, we may assume that TA also affects the cholinergic neuromuscular transmission in Lymnaea as well. Activity of AChE eliminates the released neurotransmitter from the synaptic cleft; therefore, decreased AChE activity may initially result in enhanced ACh-mediated stimulatory effects, followed by the impairment all the neuronal mechanisms where cholinergic neurotransmission is involved, acting both centrally and on the peripheral muscles. We cannot exclude, therefore, that the compound behavioural alterations we observed in the presence of TA (an initial stimulation followed by decreased activity) were the results of the above-mentioned biphasic effect of AChE inhibition.

The feeding assay we applied (Kemenes et al. 1986) allows the analysis of both the appetitive and consummatory phases of feeding controlled by peripheral and central neuronal mechanisms. Feeding latency is primarily determined by activation of the chemoreceptors around the lip and the chemosensory pathways projecting to the CNS. The rhythmically organized feeding movements (rasping) during the consummatory phase are executed by the buccal musculature, which cyclic activity is driven by the CPG network in the CNS (Benjamin 1983). The two components of feeding can be selectively affected by specific neurotoxins. For example, treatment of intact animals by rotenone, a dopaminergic neurotoxin, did not alter the feeding latency but decreased the feeding rate suggesting its target is likely located centrally, as part of the dopaminergic system in the CNS (Vehovszky et al. 2007). Therefore, our feeding results on intact animals showing that both latency and feeding rate were altered in the presence of TA initially suggested inhibitory effects of both the peripheral (sensory) and central mechanisms regulating the feeding behaviour of Lymnaea.

\section{Neurophysiological changes in the feeding system evoked by TA}

Our experiments on semi-intact preparations demonstrated that application of TA prior to the sucrose feeding test inhibited the appearance of the neuronal feeding response (rhythmic pattern of intracellular activity) to sucrose. This lack of sucrose response shows that the CPG network did not trigger the feeding rhythm, either due to peripheral impairment (receptor blocking) or direct central inhibitory mechanisms. TA has a bitter taste similarly to quinine and, therefore, may represent a negative feeding stimulus for Lymnaea (Staras et al. 1999a, b). Supporting the second option (inhibition of central processes by TA effect), a very recent work suggests the presence of subpopulations of chemosensory neurons, which may transmit direct (both stimulatory and inhibitory) sensory modalities to the CPG network in Lymnaea (Straub et al. 2004). 
Electrophysiological results, moreover, also revealed that TA did not alter the potential of the pattern generating interneurons to trigger feeding activity in the central network. Dopamine applied on the isolated CNS evoked fictive feeding in the presence of $100 \mu \mathrm{M}$ TA, and this rhythmic activity showed the same qualitative and quantitative characteristics as recorded in normal saline. Consequently, we can exclude a direct effect of TA on the central network of feeding activity, responsible for the weaker neuronal response to sucrose in semi-intact preparations or lower feeding rate of intact animals. Instead, it is more likely, that TA blocks the peripheral afferent pathways running to the CNS, by inhibiting the chemosensory receptors involved in feeding. This is also suggested by literature data obtained on insect larvae which demonstrated the blocking effect of tannins on peripheral sucrose sensitive sensory cells (Denno and McClure 1983; Dethier 1982; Panzuto et al. 2002). Additionally, as we already mentioned for locomotion above, we may also assume a direct (AChE blocking) effect of TA on the buccal musculature, which cholinergic innervation has also been described in different snails (Yoshida and Kobayashi 1991; Jordan et al. 1993).

In summary, we conclude that allelochemicals of plant origin may be an important, yet little investigated, component affecting the behaviour of the invertebrate fauna living in the aquatic environment, hence influencing the complex life of the entire ecosystem in the long term. Accordingly, our future research would include double aims. First, the putative effect(s) of tannins extracted from endemic plant species of Lake Balaton on different behaviours (feeding, locomotion) of Lymnaea stagnalis will be studied. Second, we see a potential to widen our analysis on other, non-gastropod invertebrate, first of all zooplankton species, as well as the ruling biofouling invasive bivalve, Dreissena sp.

Acknowledgements Open access funding provided by MTA Centre for Ecological Research (MTA ÖK). This project was supported by grants of the Hungarian Scientific Research Fund (OTKA), Nos. K111990 (K. Elekes) and K112712 (J. Győri).

\section{Compliance with ethical standards}

Conflict of interest The author(s) declare that they have no competing interests.

Open Access This article is distributed under the terms of the Creative Commons Attribution 4.0 International License (http://creativeco mmons.org/licenses/by/4.0/), which permits unrestricted use, distribution, and reproduction in any medium, provided you give appropriate credit to the original author(s) and the source, provide a link to the Creative Commons license, and indicate if changes were made.

\section{References}

Afghan BK, Chau ASY (2017) Analysis of trace organics in the aquatic environment. CRC Press, Boca Raton

Anku WW, Messai A, Mamo MA, Govender PP (2017) Phenolic compounds in water: sources, reactivity, toxicity and treatment methods. In: Soto-Hernandez MP-T, del Rosario Garcia-Mateos M (eds) Phenolic compounds-natural sources, importance and applications, Ch 17. TechOpen, London. https://doi.org/10.5772/66927

Appel HM, Schultz JC (1994) Oak tannins reduce effectiveness of thuricide (Bacillus thuringiensis) in the gypsy-moth (Lepidoptera, Lymantriidae). J Econ Entomol 87(6):1736-1742. https://doi. org/10.1093/jee/87.6.1736

Arundell M, Patel BA, Straub V, Allen MC, Janse C, O'Hare D, Parker K, Gard PR, Yeoman MS (2006) Effects of age on feeding behavior and chemosensory processing in the pond snail, Lymnaea stagnalis. Neurobiol Aging 27(12):1880-1891. https://doi. org/10.1016/j.neurobiolaging.2005.09.040

Benjamin PR (1983) Gastropod feeding: behavioural and neural analysis of a complex multicomponent system. Symp Soc Exp Biol 37:159-193

Benjamin PR (2012) Distributed network organization underlying feeding behavior in the mollusk Lymnaea. Neural Syst Circuits 2:4. https://doi.org/10.1186/2042-1001-2-4

Benjamin PR, Elliott CJH (1989) Snail feeding oscillator: the central pattern generator and its control by modulatory interneurons. In: Jacklet JW (ed) Neuronal and cellular oscillators. Marcel Dekker, New York, pp 173-214

Chase R (2002) Behavior and its neural control in gastropod molluscs. Oxford University Press, New York

Choi C, Bareiss C, Walenciak O, Gross EM (2002) Impact of polyphenols on growth of the aquatic herbivore Acentria ephemerella. J Chem Ecol 28(11):2245-2256. https://doi. org/10.1023/A:1021049332410

Coley PD, Bryant JP, Chapin FS (1985) Resource availability and plant antiherbivore defense. Science 230(4728):895-899. https ://doi.org/10.1126/science.230.4728.895

Croll RP, Chiasson BJ (1989) Postembryonic development of serotonin-like immunoreactivity in the central nervous-system of the snail, Lymnaea stagnalis. J Comp Neurol 280(1):122-142. https://doi.org/10.1002/cne.902800109

Das S, Khangarot BS (2011) Bioaccumulation of copper and toxic effects on feeding, growth, fecundity and development of pond snail Lymnaea luteola L. J Hazard Mater 185(1):295-305. https ://doi.org/10.1016/j.jhazmat.2010.09.033

Denno RF, McClure MS (1983) Variable plants and herbivores in natural and managed systems. Academic Press, San Diego, p 185

Dethier VG (1982) Mechanism of host-plant recognition. Entomol Exp Appl 31(1):49-56. https://doi.org/10.1111/j.1570-7458.1982. tb03118.x

Dhara K, Saha NC, Maiti AK (2017) Studies on acute and chronic toxicity of cadmium to freshwater snail Lymnaea acuminata (Lamarck) with special reference to behavioral and hematological changes. Environ Sci Pollut Res 24(35):27326-27333. https ://doi.org/10.1007/s11356-017-0349-8

Elliott CJH, Benjamin PR (1985) Interactions of the slow oscillator interneuron with feeding pattern-generating interneurons in Lymnaea stagnalis. J Neurophysiol 54(6):1412-1421

Feeny P (1976) Plant apparency and chemical defense. Recent Adv Phytochem 10:1-40

Filla A, Hiripi L, Elekes K (2009) Role of aminergic (serotonin and dopamine) systems in the embryogenesis and different embryonic behaviors of the pond snail, Lymnaea stagnalis. Comp 
Biochem Physiol C Toxicol Pharmacol 149(1):73-82. https://doi. org/10.1016/j.cbpc.2008.07.004

Ford AT, Hyett B, Cassidy D, Malyon G (2018) The effects of fluoxetine on attachment and righting behaviours in marine ( $\mathrm{Gib}$ bula unbilicalis) and freshwater (Lymnea stagnalis) gastropods. Ecotoxicology 27(4):477-484. https://doi.org/10.1007/s1064 6-018-1919-3

Gollucke APB, Aguiar O, Barbisan LF, Ribeiro DA (2013) Use of grape polyphenols against carcinogenesis: putative molecular mechanisms of action using in vitro and in vivo test systems. J Med Food 16(3):199-205. https://doi.org/10.1089/jmf.2012.0170

Graca MAS, Barlocher F (1999) Proteolytic gut enzymes in Tipula caloptera-interaction with phenolics. Aquat Insects 21(1):11-18. https://doi.org/10.1076/aqin.21.1.11.4542

Gross EM, Meyer H, Schilling G (1996) Release and ecological impact of algicidal hydrolyzable polyphenols in Myriophyllum spicatum. Phytochemistry 41:133-138

Harbertson JF, Hodgins RE, Thurston LN, Schaffer LJ, Reid MS, Landon JL, Ross CF, Adams DO (2008) Variability of tannin concentration in red wines. Am J Enol Vitic 2:210-214

Haukioja E (2005) Plant defenses and population fluctuations of forest defoliators: mechanism-based scenarios. Ann Zool Fennici 42(4):313-325

Haukioja E, Neuvonen S (1985) The relationship between size and reproductive potential in male and female Epirrita autumnata (Lep, Geometridae). Ecol Entomol 10(3):267-270. https://doi. org/10.1111/j.1365-2311.1985.tb00723.x

Jordan R, Cohen KP, Kirk MD (1993) Control of intrinsic buccal muscles by motoneuron-B11, motoneuron-B15, and motoneuron-B16 in Aplysia californica. J Exp Zool 265(5):496-506. https://doi. org/10.1002/jez.1402650505

Kemenes G, Elliott CJH, Benjamin PR (1986) Chemical and tactile inputs to the Lymnaea feeding system-effects on behavior and neural circuitry. J Exp Biol 122:113-137

Kemenes G, Hiripi L, Benjamin PR (1990) Behavioral and biochemical changes in the feeding system of Lymnaea induced by the dopamine and serotonin neurotoxins 6-hydroxydopamine and 5,6-dihydroxytryptamine. Philos Trans R Soc Lond Ser B Biol Sci 329(1254):243-255. https://doi.org/10.1098/rstb.1990.0168

Kemenes G, Staras K, Benjamin PR (1997) In vitro appetitive classical conditioning of the feeding response in the pond snail Lymnaea stagnalis. J Neurophysiol 78(5):2351-2362

Kim MS, Lee DY, Sung SH, Jeon WK (2018) Anti-cholinesterase activities of hydrolysable tannins and polyhydroxytriterpenoid derivatives from Terminalia chebula Retz. fruit. Rec Nat Prod 12(3):285-290. https://doi.org/10.25135/rnp.29.17.07.130

Krajcs N, Hernadi L, Elekes K, Kimura S, Kiss T (2014) Excitatory neurotransmitters in the tentacle flexor muscles responsible for space positioning of the snail olfactory organ. Invert Neurosci 14(1):59-69. https://doi.org/10.1007/s10158-013-0164-y

Kyriakides MA, Mccrohan CR (1989) Effect of putative neuromodulators on rhythmic buccal motor output in Lymnaea stagnalis. J Neurobiol 20(7):635-650. https://doi.org/10.1002/neu.480200704

Li YK, Yu D, Yan X (2004) Are polyphenolics valuable in anti-herbivory strategies of submersed freshwater macrophytes? Archiv für Hydrobiologie 161:391-402. https://doi. org/10.1127/0003-9136/2004/0161-0391

Magoski NS, Bauce LG, Syed NI, Bulloch AGM (1995) Dopaminergic transmission between identified neurons from the mollusk, Lymnaea stagnalis. J Neurophysiol 74(3):1287-1300

Marin L, Miguelez EM, Villar CJ, Lombo F (2015) Bioavailability of dietary polyphenols and gut microbiota metabolism: antimicrobial properties. Biomed Res Int. https://doi.org/10.1155/2015/905215

McCrohan CR, Kyriakides MA (1989) Cerebral interneurones controlling feeding motor output in the snail Lymnaea stagnalis. J Exp Biol 147:361-374
Panchin YV, Sadreev RI, Arshavsky YI (1995) Control of locomotion in marine mollusk Clione limacina. 10. Effects of acetylcholine antagonists. Exp Brain Res 106(1):135-144

Panzuto M, Mauffette Y, Albert PJ (2002) Developmental, gustatory, and behavioral responses of leafroller larvae, Choristoneura rosaceana, to tannic acid and glucose. J Chem Ecol 28(1):145160. https://doi.org/10.1023/A:1013571020783

Pavlova GA (2010) Muscular waves contribute to gliding rate in the freshwater gastropod Lymnaea stagnalis. J Comp Physiol A Neuroethol Sens Neural Behav Physiol 196(4):241-248. https://doi. org/10.1007/s00359-010-0509-5

Pavlova GA (2013) Sole smooth muscle states determine gliding rate in the freshwater snail Lymnaea stagnalis. Biol Bull 225(3):184193. https://doi.org/10.1086/Bblv225n3p184

Pavlova GA (2019) The similarity of crawling mechanisms in aquatic and terrestrial gastropods. J Comp Physiol A Neuroethol Sens Neural Behav Physiol 205(1):1-11. https://doi.org/10.1007/s0035 9-018-1294-9

Pyatt AJ, Pyatt FB, Pentreath VW (2002) Lead toxicity, locomotion and feeding in the freshwater snail, Lymnaea stagnalis (L.). Invert Neurosci 4(3):135-140. https://doi.org/10.1007/s1015 8-001-0015-0

Rawani A, Ghosh A, Chandra G (2014) Laboratory evaluation of molluscicidal \& mosquito larvicidal activities of leaves of Solanum nigrum L. Indian J Med Res 140:285-295

Rittschof D, McClellan-Green P (2005) Molluscs as multidisciplinary models in environment toxicology. Mar Pollut Bull 50(4):369373. https://doi.org/10.1016/j.marpolbul.2005.02.008

Salánki J, Farkas A, Kamardina T, Rózsa KS (2003) Molluscs in biological monitoring of water quality. Toxicol Lett 140:403-410. https://doi.org/10.1016/S0378-4274(03)00036-5

Salminen JP, Karonen M (2011) Chemical ecology of tannins and other phenolics: we need a change in approach. Funct Ecol 25(2):325338. https://doi.org/10.1111/j.1365-2435.2010.01826.x

Scalbert A, Williamson G (2000) Dietary intake and bioavailability of polyphenols. J Nutr 130(8):2073s-2085s

Serrano J, Puupponen-Pimia R, Dauer A, Aura AM, Saura-Calixto F (2009) Tannins: current knowledge of food sources, intake, bioavailability and biological effects. Mol Nutr Food Res 53:S310 S329. https://doi.org/10.1002/mnfr.200900039

Sidorov AV, Kazakevich VB (2001) Dependence of electric activity of motoneurons and locomotor behavior of Lymnaea stagnalis on environmental temperature. J Evol Biochem Physiol 37(3):252257. https://doi.org/10.1023/A:1012667206908

Sieniawska E (2015) Activities of tannins-from in vitro studies to clinical trials. Nat Prod Commun 10(11):1877-1884

Singh A, Singh DK, Misra TN, Agarwal RA (1996) Molluscicides of plant origin. Biol Agric Hortic 13(3):205-252. https://doi. org/10.1080/01448765.1996.9754782

Skrovankova S, Sumczynski D, Mlcek J, Jurikova T, Sochor J (2015) Bioactive compounds and antioxidant activity in different types of berries. Int J Mol Sci 16(10):24673-24706. https://doi. org/10.3390/ijms161024673

Smeriglio A, Barreca D, Bellocco E, Trombetta D (2017) Proanthocyanidins and hydrolysable tannins: occurrence, dietary intake and pharmacological effects. Br J Pharmacol 174(11):1244-1262. https://doi.org/10.1111/bph.v174.11/issuetoc

Staras K, Kemenes G, Benjamin PR (1998) Neurophysiological correlates of unconditioned and conditioned feeding behavior in the pond snail Lymnaea stagnalis. J Neurophysiol 79(6):3030-3040

Staras K, Kemenes G, Benjamin PR (1999a) Cellular traces of behavioral classical conditioning can be recorded at several specific sites in a simple nervous system. J Neurosci 19(1):347-357

Staras K, Kemenes G, Benjamin PR (1999b) Electrophysiological and behavioral analysis of lip touch as a component of the food stimulus in the snail Lymnaea. J Neurophysiol 81(3):1261-1273 
Straub VA, Styles BJ, Ireland JS, O'Shea M, Benjamin PR (2004) Central localization of plasticity involved in appetitive conditioning in Lymnaea. Learn Mem 11(6):787-793. https://doi.org/10.1101/ $\operatorname{lm} .77004$

Tikkanen OP, Niemela P, Keranen J (2000) Growth and development of a generalist insect herbivore, Operophtera brumata, on original and alternative host plants. Oecologia 122(4):529-536. https://doi. org/10.1007/s004420050976

Vehovszky A, Elliott CJH (2001) Activation and reconfiguration of fictive feeding by the octopamine-containing modulatory OC interneurons in the snail Lymnaea. J Neurophysiol 86(2):792-808. https://doi.org/10.1152/jn.2001.86.2.792

Vehovszky A, Elliott CJH, Voronezhskaya EE, Hiripi L, Elekes K (1998) Octopamine: a new feeding modulator in Lymnaea. Philos Trans R Soc B Biol Sci 353(1375):1631-1643. https://doi. org/10.1098/rstb.1998.0315

Vehovszky A, Szabo H, Elliott CJH (2004) Octopamine-containing (OC) interneurons enhance central pattern generator activity in sucrose-induced feeding in the snail Lymnaea. J Comp Physiol A
Neuroethol Sens Neural Behav Physiol 190(10):837-846. https:// doi.org/10.1007/s00359-004-0539-y

Vehovszky A, Szabo H, Hiripi L, Elliott CJH, Hernadi L (2007) Behavioural and neural deficits induced by rotenone in the pond snail Lymnaea stagnalis. A possible model for Parkinson's disease in an invertebrate. Eur J Neurosci 25(7):2123-2130. https://doi.org /10.1111/j.1460-9568.2007.05467.x

Walker RJ, Holden-Dye L (1991) Evolutionary aspects of transmitter molecules, their receptors and channels. Parasitology 102:S7-S29. https://doi.org/10.1017/S0031182000073261

Yoshida M, Kobayashi M (1991) Neural control of the buccal muscle movement in the African giant snail Achatina fulica. J Exp Biol $155: 415-433$

Publisher's Note Springer Nature remains neutral with regard to jurisdictional claims in published maps and institutional affiliations. 